\title{
Importance of proximity to resources, social support, transportation and neighborhood security for mobility and social participation in older adults: results from a scoping study
}

Mélanie Levasseur ${ }^{1,2^{*}}$, Mélissa Généreux ${ }^{1,2,3}$, Jean-François Bruneau ${ }^{1,4}$, Alain Vanasse ${ }^{1,5}$, Éric Chabot ${ }^{6}$, Claude Beaulac ${ }^{6}$ and Marie-Michèle Bédard ${ }^{1}$

\begin{abstract}
Background: Since mobility and social participation are key determinants of health and quality of life, it is important to identify factors associated with them. Although several investigations have been conducted on the neighborhood environment, mobility and social participation, there is no clear integration of the results. This study aimed to provide a comprehensive understanding regarding how the neighborhood environment is associated with mobility and social participation in older adults.

Methods: A rigorous methodological scoping study framework was used to search nine databases from different fields with fifty-one keywords. Data were exhaustively analyzed, organized and synthesized according to the International Classification of Functioning, Disability and Health (ICF) by two research assistants following PRISMA guidelines, and results were validated with knowledge users.

Results: The majority of the 50 selected articles report results of cross-sectional studies (29; $58 \%$ ), mainly conducted in the US $(24 ; 48 \%)$ or Canada $(15 ; 30 \%)$. Studies mostly focused on neighborhood environment associations with mobility (39; $78 \%)$, social participation (19; $38 \%)$, and occasionally both (11; $22 \%)$. Neighborhood attributes considered were mainly 'Pro ducts and technology' (43; 86 ) and 'Services, systems and policies' (37; 74\%), but also 'Natural and human-made changes' (27; $54 \%)$ and 'Support and relationships' (21; $42 \%)$. Mobility and social participation were both positively associated with Proximity to resources and recreational facilities, Social support, Having a car or driver's license, Public transportation and Neighborhood security, and negatively associated with Poor user-friendliness of the walking environment and Neighborhood insecurity. Attributes of the neighborhood environment not covered by previous research on mobility and social participation mainly concerned 'Attitudes', and 'Services, systems and policies'.

(Continued on next page)
\end{abstract}

\footnotetext{
* Correspondence: Melanie.Levasseur@USherbrooke.ca

'University of Sherbrooke, 2500 University Blvd., J1K 2R1 Sherbrooke, QC, Canada

${ }^{2}$ Research Centre on Aging, Health and Social Services Centre - University Institute of Geriatrics of Sherbrooke, 1036 Belvedere South, J1H 4C4

Sherbrooke, QC, Canada

Full list of author information is available at the end of the article
} 
(Continued from previous page)

Conclusion: Results from this comprehensive synthesis of empirical studies on associations of the neighborhood environment with mobility and social participation will ultimately support best practices, decisions and the development of innovative inclusive public health interventions including clear guidelines for the creation of age-supportive environments. To foster mobility and social participation, these interventions must consider Proximity to resources and to recreational facilities, Social support, Transportation, Neighborhood security and User-friendliness of the walking environment. Future studies should include both mobility and social participation, and investigate how they are associated with 'Attitudes', and 'Services, systems and policies' in older adults, including disadvantaged older adults.

Keywords: Neighborhood environment, Mobility, Social participation, Older adults, Quality of life, Scoping study

\section{Background}

Older adults make up a sizeable proportion of the population that will, between 2000 and 2050, double from about 11 to $22 \%$, including almost 400 million people worldwide aged 80 years or older [1]. Many people aged 65 and older suffer from chronic diseases such as arthritis and rheumatism (47.3\%), hypertension (42.8\%), heart disease (19.8\%) or diabetes (13.5\%), and almost half (42\%) have disabilities [2], which have significant consequences for individuals, communities, and social and health services. Chronic diseases and disabilities can be prevented or delayed by public health interventions (e.g., urban planning) as well as by clinical interventions (e.g., physician preventive practices) focusing on major modifiable health determinants. In comparison to the current population, future generations of older adults will likely have a better expectancy of years in good health [2] and, as a result, a larger proportion will have the potential for longer exposure to higher levels of mobility and social participation.

Social participation and mobility are major modifiable determinants of older adults' health and key dimensions of successful aging [3]. On the one hand, mobility is broadly defined as "the ability to move oneself (e.g., by walking, using assistive devices, or taking transportation) within community environments that expand from one's home, to the neighbourhood, and to regions beyond" [4]. It can be qualified in relation to life-space, from home to community. Mobility disability is common among older adults $[5,6]$. For example, in Canada, more than 2.4 million people (10.5\%) [7] and approximately half of people aged 65 and older have restricted mobility [2, 4]. As a critical element of older adults' health, diminished mobility has been associated with being physically inactive [8-11], obesity $[8,10,12]$, physical disability [13-16], lower quality of life $[13,17,18]$, premature mortality $[19-21]$ and increased health care costs $[22,23]$. Moreover, older adults participate more frequently in social activities if, especially when driving is not possible, they have access to private or public transportation. Community mobility using transportation, especially active or public transportation, is favorable to older adults' health [24]. Sustainable modes of transportation simultaneously encourage physical activity and reduce local traffic-related pollution, both known to be associated with cardiovascular and other chronic diseases [25]. Access to public transportation for people living in rural areas may be limited, which can be a challenge [26]. Living in metropolitan, urban or rural areas can have an impact on many personal factors such as health and well-being, as well as on several environmental factors such as neighborhood socioeconomic status or access to services and transportation. To be closer to services, some older adults have moved from a rural to an urban area. In addition to individual factors such as health problems that affect muscle strength and balance, some environmental challenges such as constraints that involve physical loading and postural transitions (e.g., sloping terrain or stairs) can specifically influence mobility [27, 28].

On the other hand, social participation can be defined as "a person's involvement in social activities that provide social interactions within his/her community or society" [29]. Specifically, social participation has been found to be a determinant of many favorable health and quality of life outcomes [30]. Identified as protecting against cognitive decline among community-dwelling older persons [31], social participation has been shown to be closely related to mobility in the community [32] and at home [33]. However, social participation declines as a result of the 'normal' aging process [34, 35] and, when limited, has been shown to be associated with mortality [36] and morbidity [37]. Greater disabilities and lack of neighborhood resources can restrict social participation [38] and decrease the likelihood of independent living [15]. In fact, disability, defined as any disturbance resulting from an impairment in the capacity to perform a physical or mental activity considered normal for a human being [39], has been found to be one of the most powerful determinants of social participation [40-50].

Interventions targeting environmental factors may have a greater impact on individual and population mobility and social participation than those targeting individual factors [51], including disability. The environment is defined by "the physical and social characteristics in which people live" [52] and, according to the International Classification of 
Functioning, Disability and Health (ICF) [53], includes five domains (chapters): 1) 'Products and technology', 2) 'Natural environment and human-made changes', 3) 'Support and relationships', 4) 'Attitudes', and 5) 'Services, systems and policies' (Appendix 1). Among the characteristics of the environment, neighborhood living conditions are important for health and well-being, especially for older adults. Compared to adults in the workforce, older adults are more place-bound $[54,55]$, i.e., spend more time each day in their neighborhood and stay longer in the same residential environment $[2,56]$. Based on the definition of the physical environment of Davison and Lawson [57], neighborhood environment represents characteristics of the physical context including attributes of urban design (e.g., presence of sidewalks), traffic density and speed, distance to and design of venues for physical activity such as walking (e.g., parks and access to services), esthetics, crime and safety. Since mobility is also influenced by the social environment [4], i.e., 'Support and relationships', 'Attitude', 'Services, systems and policies', it is necessary to consider both physical and social neighborhood attributes and not only the built environment. Compared to younger adults, older people spend less time in structured employment activities and have more time to participate in other activities and be exposed to the neighborhood environment.

Since social participation and mobility can be enhanced [58], a clearer understanding of how environmental factors are associated with older adults is essential for informing and improving clinical [59] and public health [60] interventions such as age-friendly cities [61]. As illustrated by Lawton [51] and Glass and Balfour [56], two models widely used in public health, neighborhood facilitators (i.e., helpful factors, such as prostheses, resources and opportunities) can support personal capacities such as mobility, which can in turn enable greater social participation $[51,56]$. In contrast, environmental obstacles (e.g., physical barriers, inaccessibility of services and amenities, social stress, and resource inadequacy) can challenge and exceed personal capacities, thereby limiting social participation. Support from the social environment [56, 62] and accessibility in the physical neighborhood environment $[53,56,63-65]$ are seen as imperatives for helping individuals with disabilities living in the community [56, 66, 67].

Among neighborhood characteristics, living in close proximity to services $[68,69]$ has been shown to be important in performing activities to meet daily needs, including access to food shopping, health services, public transportation, banking and social clubs. Such proximity to services also contributes to initiating and maintaining social links with community members [69, 70]. Older adults living in resource affluent areas are less likely to have low levels of social functioning, independently of individual demographic (e.g. age) and socioeconomic (e.g. income) characteristics [71]. Individuals' perceptions of the area as neighborly and having good facilities were also independently associated with a greater likelihood of social activities [71, 72] and well-being [73]. Walking distance, weather conditions, terrain characteristics, external physical loads, demands on attention, and traffic levels can all influence community mobility [13, 74-76] and social participation [77]. Finally, architectural (e.g., porches) and neighborhood design features can promote interaction among individuals in a neighborhood [78].

Despite the results of these studies and widespread acceptance of the importance of the neighborhood environment for mobility and social participation, a rigorous, integrative and comprehensive portrait is still lacking. Scoping studies are specifically designed to "... identify gaps in the evidence base where no research has been conducted" and to "... summarise and disseminate research findings" [79]. As for a systematic review, scoping methodology follows rigorous steps and a systematic process of study selection. This rigorous method considers both quantitative and qualitative research, and involves summarizing the results of studies to provide comprehensive evidence-based knowledge without specifically pooling the data or evaluating the quality of the studies. This scoping study thus aimed to provide a comprehensive understanding of how a wide range of physical and social neighborhood attributes is associated with or influences mobility and social participation in older adults. Such a synthesis of current knowledge represents an original contribution and may ultimately support decisions and the development of innovative interventions, clear guidelines and best practices regarding developing a neighborhood environment that enhances mobility and social participation in older adults.

\section{Methods}

The methodological framework for scoping studies [79-82] was used to synthesize and disseminate current knowledge on the associations or influence of the neighborhood environment on mobility and social participation in aging [83]. The framework for the scoping study [79-82] includes collaboration between researchers and knowledge-users in the seven stages that were followed: i) identifying the research questions, ii) identifying relevant studies, iii) selecting the studies, iv) charting the data, v) collating, summarizing and reporting results, vi) consulting (throughout the project), and vii) dissemination of results.

\section{Identifying the research questions}

Three questions were specifically addressed:

1) What are the social and physical attributes of the neighborhood environment which have been shown 
to be associated with or influence mobility and social participation in older adults?

2) How is the neighborhood environment associated with or how does it influence mobility and social participation in older adults?

3) Which attributes of the neighborhood environment have not been covered by previous research on mobility and social participation in older adults?

\section{Identifying relevant studies}

The search involved nine databases (Medline, Cochrane Database of Systematic Reviews, CINAHL, Ageline, SocIndex, Psycinfo, Allied \& Complementary Medicine Database (AMED), Academic Search Complete, Francis), fifty-one specific related keywords (Table 1) and targeted studies published in English and French between January 1980 and September 2013.

\section{Selecting the studies, charting the data, and collating, summarizing and reporting results}

Two research assistants specifically trained and supervised by the principal researcher and information scientist, separately screened relevant articles by title and, when available, by abstract. To ensure transparency and reproducibility of the process [80], following PRISMA guidelines [84], all studies that comprehensively inform about the associations or influence of the neighborhood environment on mobility and social participation were retained and identified on a flow chart (Fig. 1). The selection of relevant literature was restricted, though not exclusively (retained if results specific to adults were also included), to papers on older adults. Extended

Table 1 Keywords chosen $(n=51)$

Keywords [strategy: 1. Built environment OR neighbourhood OR

1 AND 2 AND neighborhood OR environment* design* OR

(3 OR 4)] $\quad$ universal design* OR physical environment $O R$ healthy environment $O R$ living environment $O R$ urban environment* OR suburban environment* OR rural environment* OR public transport* OR alternative transport* OR public transit OR paratransit OR bus OR buses OR urban design OR walkability OR walkable OR pedestrian OR social environment $\mathrm{OR}$ community design

2. Elder* OR seniors OR old* adult* OR geriatric OR aged $O R$ ageing $O R$ aging $O R$ older people

3. Community participation OR social participation OR social involvement OR social engagement OR community involvement OR community engagement OR civic participation OR social isolation OR social integration OR social contact* OR social activity* OR social inclusion* OR social interaction* OR solitude OR loneliness OR lonely OR social exclusion*

4. Mobility OR walking OR active transport*

$\ddagger$ To include all categories of keywords, the search strategy was more complex than presented here and is available upon request to the corresponding author search strategies included other studies found with a manual search of bibliographies and journals of interest (e.g., Health \& Place, Annual Review of Public Health, and BMC Public Health). Relevant studies proposed by the team members and selected experts in the field of public health, rehabilitation and gerontology were also included (Fig. 1). Studies were excluded if they: 1) focused on narrow concepts (e.g., only on participation in a seniors' centre or volunteering or home mobility, nursing home, gait, fear, migration, rehabilitation, physical functions, car settings, physical activity other than walking, daily activity, volunteering) or broader ones (e.g., exclusively on sociocultural, economic or policy attributes of the environment), 2) reported expert opinions or conference proceedings (often not providing sufficient information), or 3) concerned specific populations (e.g., people with diabetes or visual problems). The research assistants met regularly with the principal researcher and, at the beginning and in the middle of this process, with all team members to discuss and resolve any ambiguities concerning study selection, charting the data, or collating, summarizing and reporting results. An evolving data charting form [80] developed for this study and the definitions of all chapters of the environmental factors of the ICF (Appendix 1) [53] were used to classify the results independently extracted and categorized by the two research assistants and validated by the team. Content analysis procedures were followed where categories were grouped by meaning, synthesized, and then classified into coherent, consistent, relevant, clearly defined and productive themes [85]. This analysis also considered disadvantaged older adults, i.e., those with low income, minority status (e.g., race, ethnicity, gender, sexual orientation), limited education, frailty, or poor health (physical or mental). Such qualitative methods of analyzing documents ensure credibility and strength of the results [80]. Finally, a third team meeting was held to discuss the results with content experts and knowledge-users, identify implications and ensure clinical relevance of the results.

\section{Results}

Of the 4802 papers retrieved through the electronic search, 49 met the inclusion criteria and one was added by the extended search strategies (Fig. 1). The year of publication of the papers ranged from 1997 to 2013 (Table 2). Half (number and percentage of papers: $25 ; 50 \%$ ) were published after 2009, with the most productive years being 2010, 2011, and 2012 (7, 8 and 8 respectively). About one third came from the field of gerontology $(19 ; 38 \%)$, another third from public health $(17 ; 34 \%)$ and approximately one fifth from rehabilitation $(8 ; 16 \%)$. Most papers exclusively concerned older adults $(53 ; 86 \%)$ and predominantly used the term neighborhood $(27 ; 54 \%)$ or environment (21; $42 \%)$. The majority of the 50 selected articles reported 


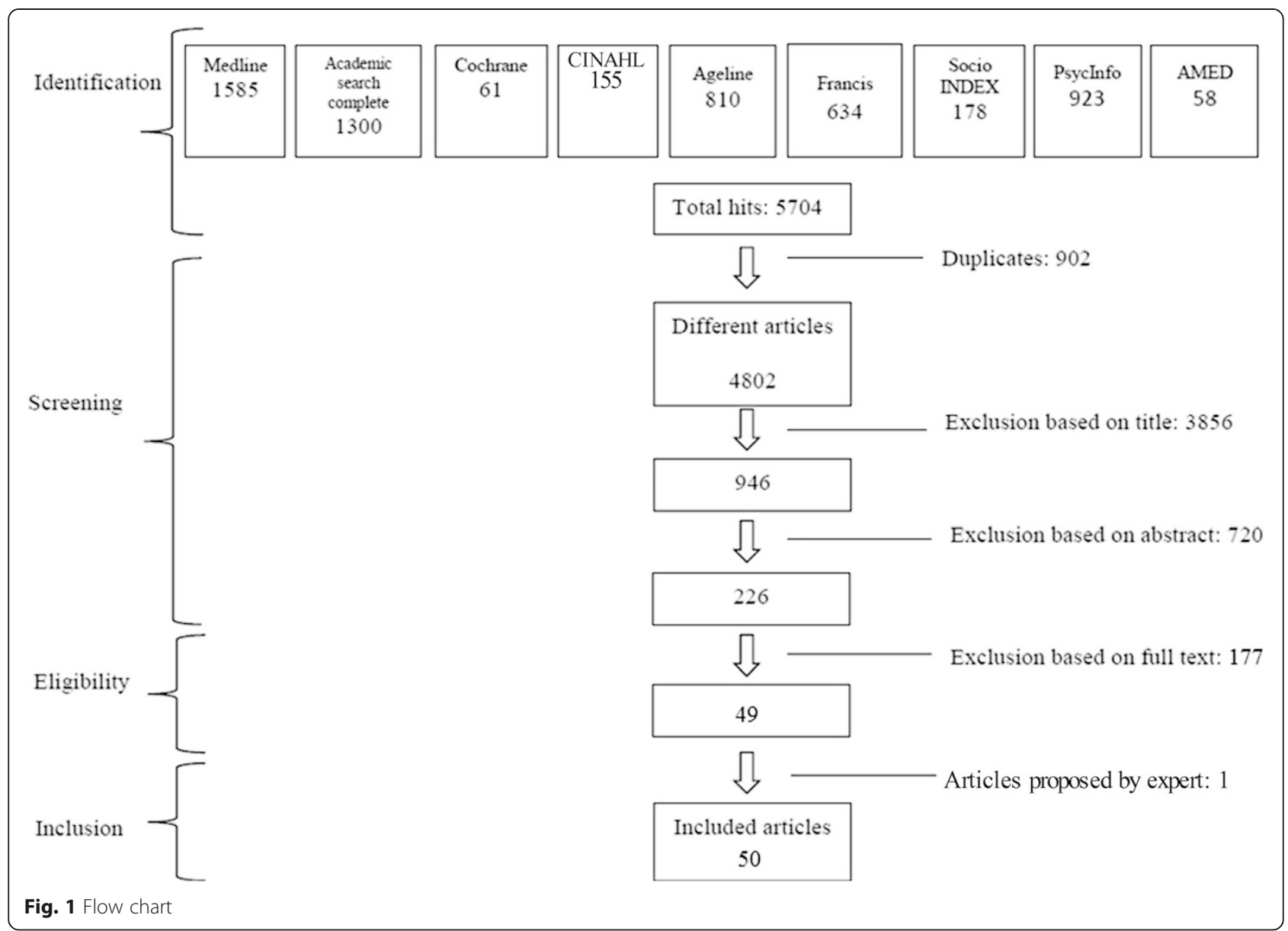

results of cross-sectional studies (29; $58 \%$ ), mainly conducted in the US $(24 ; 48 \%)$ or Canada $(15 ; 30 \%)$, and a few were carried out with disadvantaged older adults, i.e., persons with disabilities $(6 ; 12 \%)$ or Low Neighborhood Socioconomic Status (2; 4 \%; Table 2). Studies mostly focused on neighborhood environment associations with mobility (39; $78 \%$ ), social participation (19; $38 \%$ ), and occasionally both $(11 ; 22 \%)$. More than one third (18; $36 \%)$ of the studies involved 150 participants or less, and about one fifth $(11 ; 22 \%)$ more than 1000 . Most studies were carried out in urban settings (40; $80 \%)$, and a few in rural $(7 ; 14 \%)$ or suburban $(12 ; 24 \%)$ areas (Table 2). Neighborhood measures were mainly subjective measures $(34 ; 68 \%)$, and sometimes objective $(7 ; 14 \%)$ or both $(9 ; 18 \%)$. Mobility (32; $82.1 \%)$ and social participation (19; $100 \%)$ were mostly self-reported measures, the former most commonly operationalized by walking (38; $94.4 \%$ ), but also sometimes focusing on driving $(10$; $59.0 \%)$ or active and alternative transportation (13; $33.3 \%$ ).

Neighborhood attributes considered were mainly 'Products and technology' (43; 86 \%; Table 3) and 'Services, systems and policies' (37; $74 \%$ ), but also 'Natural environment and human-made changes to environment' (27; $54 \%)$ and 'Support and relationships' (21; $42 \%)$. Among the 103 attributes studied, the majority were positively (see + in Table 3; 62; 60.2 \%) associated with mobility or social participation. Associations of mobility or social participation with neighborhood attributes were primarily positive (209; $54 \%$; Table 3$)$, but some were negative (86; $22.2 \%$ ) or non-existent (92; $23.8 \%$ ). Twenty-two divergent associations were found among the same studies, contrasting specific contexts such as people with disabilities versus without, walking versus driving. Attributes of the neighborhood environment not covered by previous research on mobility or social participation mainly concerned 'Attitudes', and 'Services, systems and policies' (Appendix 2).

Selected studies considering 'Products and technology' (Table 3) mainly focused on 'Products and technology of land development' (43; $86 \%$ ) and 'Design, construction and building products and technology of buildings for public use' (14; $28 \%)$. From these studies, mobility and social participation were both principally positively associated with Seating, Good user-friendliness of the 
Table 2 Characteristics of the articles on neighborhood environment, mobility and social participation in older adults

\begin{tabular}{|c|c|c|c|c|}
\hline $\begin{array}{l}\text { Reference } \\
\text { number }\end{array}$ & Country & Setting & Design & $\begin{array}{l}\text { Population } \\
\text { (sample size; age) }\end{array}$ \\
\hline [25] & USA & Suburban & Cross-sectional & $1970 ; 65+(65-85+)$ \\
\hline [27] & Canada USA & Urban & Cross-sectional & $36 ; 70$ \\
\hline [71] & Europe & Urban, rural & Cross-sectional & $761 ; 65-85+$ \\
\hline [72] & USA & Urban & Longitudinal & $1821 ; 45-92$ \\
\hline [86] & Europe & $\begin{array}{l}\text { Urban rural } \\
\text { suburban }\end{array}$ & Cross-sectional & 48,$879 ;<65$ \\
\hline [87] & Europe & $\begin{array}{l}\text { Urban rural } \\
\text { suburban }\end{array}$ & Qualitative & $21 ; 82-90$ \\
\hline [88] & Canada & Urban & Cross-sectional & $\begin{array}{l}296 \text { women, } 258 \\
\text { men; } 75 \text { (67-84) }\end{array}$ \\
\hline
\end{tabular}


Table 2 Characteristics of the articles on neighborhood environment, mobility and social participation in older adults (Continued)

\begin{tabular}{|c|c|c|c|c|c|}
\hline & & & & & $\begin{array}{l}\text { adults living in a downtown neighborhood of a midsized } \\
\text { Prairie city. }\end{array}$ \\
\hline [99] & Canada USA & Urban & Qualitative & $66 ; 65+$ & $\begin{array}{l}\text { To identify neighborhood social and physical environmental } \\
\text { aspects that influence older adults' physical activity. }\end{array}$ \\
\hline$[101]$ & USA & Urban suburban & Cross-sectional & $251 ; 65+$ & $\begin{array}{l}\text { To explore the ability of neighborhood design to preserve } \\
\text { accessibility for the elderly by enabling a shift from driving to } \\
\text { transit and walking, while controlling for neighborhood } \\
\text { preferences and attitudes towards transportation. }\end{array}$ \\
\hline [102] & Canada & Urban suburban & Qualitative & $75 ; 65$ & $\begin{array}{l}\text { To understand older people's neighborhood walking } \\
\text { experiences with an emphasis on daily life. }\end{array}$ \\
\hline [105] & USA & Not reported & Qualitative & $60 ; 55+$ & $\begin{array}{l}\text { To answer the research question: How does neighborhood } \\
\text { design encourage or inhibit active aging according to older } \\
\text { adults? }\end{array}$ \\
\hline$[106]$ & Canada & Not reported & Cross-sectional & $200 ; 65+$ & $\begin{array}{l}\text { To examine the effect of the environment on participation } \\
\text { while controlling for the individual's personal factors }\end{array}$ \\
\hline [107] & USA & Urban & Qualitative & $7 ; 55+$ & $\begin{array}{l}\text { To identify the strategies used to create and maintain social } \\
\text { participation for older adults living alone in the community, } \\
\text { and explore older adults' own perceptions of their experience } \\
\text { of social participation. }\end{array}$ \\
\hline [108] & USA & Urban & Longitudinal & $217 ; 70+$ & $\begin{array}{l}\text { To examine the longitudinal relationship between perceived } \\
\text { neighborhood climate and walking behavior, over a 12-month } \\
\text { period }\end{array}$ \\
\hline [109] & Asia & Urban & Cross-sectional & $484 ; 65-74$ & $\begin{array}{l}\text { To examine associations of perceived neighborhood } \\
\text { environmental attributes believed to influence walking with } \\
\text { overall and within-neighborhood recreational walking in a } \\
\text { sample of Chinese elders residing in an ultra-dense metropolis } \\
\text { with a developed public transport system (Hong Kong). }\end{array}$ \\
\hline$[110]$ & Europe & Rural suburban & Qualitative & $42 ; 65-79$ & $\begin{array}{l}\text { To obtain a qualitative assessment of the opinions of the } \\
\text { elderly living in rural areas regarding their leisure and } \\
\text { recreational habits. }\end{array}$ \\
\hline [111] & Brazil & Not reported & Cross-sectional & $1652 ; 60+$ & $\begin{array}{l}\text { To evaluate the association between safety from crime and } \\
\text { physical activity among older adults }\end{array}$ \\
\hline [112] & Europe & Urban & Longitudinal & $261 ; 75-81$ & $\begin{array}{l}\text { To identify the effect of environmental facilitators for outdoor } \\
\text { walking on development of walking difficulty in community- } \\
\text { dwelling older people. }\end{array}$ \\
\hline [113] & Europe & Not reported & Qualitative & $957 ; 81.7$ & $\begin{array}{l}\text { To describe older people's motive for and experiences of } \\
\text { mobility and occupational participation outside the home. }\end{array}$ \\
\hline [114] & USA & Urban & Qualitative & $21 ; 60+$ & $\begin{array}{l}\text { To identify the salient factors of the neighborhood } \\
\text { environment that encourage or discourage walking in older, } \\
\text { urban African Americans. }\end{array}$ \\
\hline [115] & Canada & Urban suburban & Longitudinal & $521 ; 67-84$ & $\begin{array}{l}\text { To examine whether or not closer proximity to local services } \\
\text { and amenities was associated with maintenance of more } \\
\text { frequent walking over time among urban-dwelling seniors over } \\
\text { and above individual-level characteristics. }\end{array}$ \\
\hline [116] & Asia & $\begin{array}{l}\text { Urban rural } \\
\text { suburban }\end{array}$ & Cross-sectional & $1921 ; 65-74$ & $\begin{array}{l}\text { To examine the association between perceived neighborhood } \\
\text { environment and walking for specific purposes among } \\
\text { Japanese elderly adults. }\end{array}$ \\
\hline [117] & USA & Not reported & Longitudinal & $438 ; 65+$ & $\begin{array}{l}\text { To examine participation in } 2 \text { areas: (1) social and home } \\
\text { participation, which is related to self-care and domestic } \\
\text { functioning, financial functioning, social relationships, and } \\
\text { communication; and (2) community participation, which } \\
\text { reflects participation related to a person's mobility, functioning } \\
\text { in work, and other ADLs. }\end{array}$ \\
\hline [118] & USA & Urban & Cross-sectional & $91 ; 68.7$ (64-91) & $\begin{array}{l}\text { To explore the possibility that older adult's exposure to green } \\
\text { common spaces is related to an increased sense of local } \\
\text { community because of enhanced levels of social integration. }\end{array}$ \\
\hline [119] & USA & Urban & Longitudinal & $303 ; 65+$ & $\begin{array}{l}\text { To examine change in neighborhood walking activity over a } \\
12 \text {-month period in a community-based sample. }\end{array}$ \\
\hline
\end{tabular}


Table 2 Characteristics of the articles on neighborhood environment, mobility and social participation in older adults (Continued)

\begin{tabular}{|c|c|c|c|c|}
\hline [120] & USA & Urban & Cross-sectional & $577 ; 74$ \\
\hline [121] & Europe & Urban rural & Cross-sectional & $\begin{array}{l}90 \text { neighborhoods; } \\
45-73\end{array}$ \\
\hline [122] & Canada & Urban rural & Qualitative & $22 ; 76(60-90)$ \\
\hline [123] & Canada & Suburban & Qualitative & $22 ; 62-89$ \\
\hline
\end{tabular}

To examine the relation between built environment factors and walking activity at both the neighbourhood level and the resident level, in an older adult population.

To analyze the impact of the neighborhood on individual social capital.

To examine environmental factors influencing the walking choices of elderly people.

To 1) illustrate participants' typical day in order to identify changes since 1999, that is, the strategies of 'déprise' (abandonment) and their impact on daily mobility; 2) reveal the experiences and meanings of "home" in light of changes in daily mobility during a six-year period, and with regards to elders' representations of the city and of aging; 3 ) shed light on individual reasons behind territorial mobility adaptation strategies and describe the relationship of elderly to the broader urban environment.

[124] USA Urban Cross-sectional 4317; 65+

To examine individual differences in walking behavior among community-dwelling older adults in relation to two features of the neighborhood environment-social cohesion and exchange, and neighborhood disorder.

To examine the degree of association between perceived and objective characteristics of the neighborhood environment and the relation of each type of measurement to neighborhood walking in older adults.

To explore the relationship between pedestrian-friendly urban form as reflected in new urbanism design guidelines, and neighborhood service use, walking, driving, quality of life, and neighborhood satisfaction among older women.

To investigate the relationship between perceptions of neighbourhood user-friendliness and social participation.

To examine the associations between proximity to selected locations considered to be conducive to social participation, and social participation itself, in urban-dwelling seniors.

To determine perceptions of environmental supports for and barriers to walking and biking behavior in older adults and to evaluate whether perceptions differed by defined neighborhood walkability.

To compare participation of older adults according to the level of urbanization of their home environment, and to explore sociodemographic factors associated with participation in relation to the urbanization level of their environment.

To explore the behavior and representations of seniors concerning doing physical activities to identify obstacles to going out and walking, their need to overcome these obstacles over the long term, and communication channels to disseminate information about a walking route (translation).

To identify the perceived environmental influences on Flemish older adults' walking for transportation.

To explore the association of particular features of neighborhood environments with disability among older adults with existing functional limitations.

To understand how older adults perceive and navigate their neighborhoods, the study looked at the implications of activity in their neighborhoods for their health to identify the types of resources that people use in their residential settings to maintain or improve their overall well-being.

walking environment and Proximity to resources and to recreational facilities, and negatively associated with Poor user-friendliness of the walking environment.
Space for socialization, Esthetics, Good condition of streets/paths, Sidewalks and walking/cycling facilities were also positively associated with mobility, while 
Table 3 Synthesis of literature review of environmental factors positively (+), negatively (-) or not (0) associated with mobility and social participation in older adults

\begin{tabular}{|c|c|c|}
\hline Environment & Mobility & Social participation \\
\hline \multicolumn{3}{|l|}{ Chapter 1: Product ${ }^{*}$ and technology } \\
\hline \multicolumn{3}{|c|}{ e120: Products and technology for personal indoor and outdoor mobility and transportation } \\
\hline Mobility assistive device & $+[87],-[123]$ & $+[87], 0[117]$ \\
\hline \multicolumn{3}{|l|}{ e125: Products for communication } \\
\hline Communication technology & $+[113]$ & $+[113], 0[117]$ \\
\hline \multicolumn{3}{|c|}{ e140: Products and technology for culture, recreation and sport } \\
\hline Absence of parks and walking areas & $-[111]$ & $-[133]$ \\
\hline Community gardens & $+[99]$ & $+[99]$ \\
\hline Space for socialisation & $+[86],+[87],+[99],+[102]$ & $+[87]$ \\
\hline \multicolumn{3}{|c|}{ e150: Design, construction and building products and technology of buildings for public use } \\
\hline Absence of high ramps & $0[132]$ & \\
\hline Adequate handicap parking & $+[123],+[133]$ & $+[123]$ \\
\hline Buildings difficult to access & $-{ }^{\dagger}[93]$ & \\
\hline Escalators, curbs and uneven surfaces & $0^{\ddagger} /-^{\S}[92]$ & \\
\hline Parking & $+[93],+[99]$ & \\
\hline Public facilities & $0[90],+[114]$ & \\
\hline Seating & $\begin{array}{l}+[86],+[87],+[93],+[99],+[102],+[105], 0 /+{ }^{* *}[109] \\
+[122],+/ 0[132]\end{array}$ & $+[87],+[105], 0[133]$ \\
\hline Toilet facilities adequate for persons with disabilities & $+[93]$ & \\
\hline Universally accessible public spaces & $+[99],+[123]$ & $+[123]$ \\
\hline Washrooms & $+[99],+[122], 0[132]$ & \\
\hline Water fountains & $+[99],+[122]$ & \\
\hline \multicolumn{3}{|c|}{ e155: Design, construction and building products and technology of buildings for private use } \\
\hline Easy access of residential entrance & $0[109]$ & \\
\hline Home architectural mobility barriers & & $-{ }^{\dagger \dagger}[117]$ \\
\hline \multicolumn{3}{|l|}{ e160: Products and technology of land development } \\
\hline Aesthetics $^{\ddagger \neq}$ & $\begin{array}{l}+[86], 0[98], 0[109],+[114],+[116],+[122],+[129], \\
+[132]\end{array}$ & \\
\hline Bad condition of sidewalks & $+[114]$ & \\
\hline Bridge/overpasses connecting to services & $+[109]$ & \\
\hline Crossing & $+[86],+[132]$ & \\
\hline Dispersion of resources & $-[110],-[129]$ & $-[110]$ \\
\hline Fence separating sidewalks from traffic & 0[109] & \\
\hline Few streets & $-[96]$ & \\
\hline Good condition of streets/path & $+[87],+[90], 0[97],+[99]$ & \\
\hline Good quality of facilities & & $+[71]$ \\
\hline Good user-friendliness of the walking environment & $+[72], 0[94],+[113],+[135]$ & $+[113],+[127], 0[128]$ \\
\hline Indoor shopping areas & $+[114]$ & \\
\hline Mixed services and good pedestrian access & $+[126]$ & \\
\hline No curbs with curb cuts & & O[133] \\
\hline Uninviting neighborhood surroundings & $-[114]$ & \\
\hline Poor user-friendliness of the walking environment & 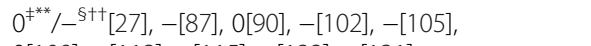 & $-[99],-[105],-/+{ }^{+\dagger}[107],-[118]$ \\
\hline
\end{tabular}


Table 3 Synthesis of literature review of environmental factors positively (+), negatively (-) or not (0) associated with mobility and social participation in older adults (Continued)

\begin{tabular}{|c|c|c|}
\hline $\begin{array}{l}\text { Poorly maintained or missing sidewalks, crosswalks, bike } \\
\text { paths or lanes }\end{array}$ & $-[129]$ & \\
\hline Garbage & $-[111]$ & \\
\hline Proximity to recreational/exercise facilities & $\begin{array}{l}0 /+^{1}[90],+[95],+[99],+[105],+[109],+[112],+[113], \\
+[114],+[116], 0[119],+[120],+[122], 0[125],+[132]\end{array}$ & $+[105],+[113]$ \\
\hline Relocation of community services and shops & $-[102],-[113]$ & $-[102],-[113]$ \\
\hline Resources proximity & $\begin{array}{l}+[86], 0 /+^{1}[90],+^{+\dagger}[93], 0^{\dagger+\neq \neq \neq} /+[94],+[96], 0[98],+[99], \\
++^{\xi^{* * * *}} /-^{++t}[101],+[102],+[105], 0 /+[115],+[116],+[120], \\
+[123],+[125],+[126],+[129],+[134]\end{array}$ & $\begin{array}{l}+[88],+[105],+[107],+[1 \\
+[123],+[127],+[128]\end{array}$ \\
\hline Rural > urban & $+^{* * *}[101]$ & \\
\hline Safe stairs & $+[99]$ & \\
\hline Sidewalks & $\begin{array}{l}+[86], 0[96],+[99],+[102],+[105], 0[111],+[114], 0[116], \\
0[125]\end{array}$ & $+[105]$ \\
\hline Streets connectivity & $+[86], 0[96], 0[98], 0[109]$ & \\
\hline Streets in poor condition & & $-{ }^{\S+\dagger} / 0[89],-{ }^{\S+\dagger} / 0^{\neq * *}[97]$ \\
\hline Streets with traffic lights and busy streets & $0^{\ddagger^{* *}} /-^{\dagger \dagger}[92]$ & \\
\hline Traffic and road hazards & 0[109] & \\
\hline Traffic lights located at inconvenient spots & $-[122]$ & \\
\hline Unfamiliar places & $0^{* * *} /-^{+\dagger \S}[92]$ & \\
\hline Urban > rural & $+{ }^{\dagger \S}[101], 0^{\ddagger \neq \ddagger} /+\S \S \S[132]$ & $++^{\dagger \neq \ddagger}[101]$ \\
\hline Urban $>$ semi-urban $>$ rural & & $+[110], 0[130]$ \\
\hline Walking/cycling facilities & $0[98],+[109], 0[111],-3 /+[114],+[116], 0[125],+[129]$ & \\
\hline e165: Assets & & \\
\hline Packages carried & $-[27]$ & \\
\hline Chapter 2: Natural environment and human-made ch & anges to environment & \\
\hline e210: Physical geography & & \\
\hline Topography physically demanding & $0[90], 0[111],-[113]$ & $-[113]$ \\
\hline e215: Population & & \\
\hline Crowded places with high traffic density & $0^{\ddagger * *} /{ }^{+\dagger \S}[92]$ & \\
\hline Living in prosperous areas & & $+[71]$ \\
\hline Low level of traffic & $+[101]$ & \\
\hline Low Neighborhood Socioeconomic Status & $+[95],+[96]$ & \\
\hline Neighborhood & & $+[121]$ \\
\hline Population density & $0[72], 0[109], 0[116],+[120]$ & \\
\hline Seniors density & $0[72],+[95]$ & \\
\hline Traffic & $+[96],-[105], 0[109], 0[111],-^{* * *}[113],-[132]$ & $+{ }^{++\S^{* * * * *}}[89],-[105], 0[113]$ \\
\hline White people density & $+[95]$ & \\
\hline e220: Flora and fauna & & \\
\hline Animals & $-/+^{2}[114]$ & \\
\hline Stray animals & $-[90]$ & \\
\hline Lack of greenery & $-[131]$ & \\
\hline Nature and green space & $+[86], 0[91],+[93],+[102], 0[111],+[114],+[129], 0[132]$ & $+[118]$ \\
\hline e225: Climate & & \\
\hline Poor weather conditions & $0^{* * \neq} /-^{\S+\dagger}[92],-[102], 0[111],-[113],-[114],-[122]$ & $-[113]$ \\
\hline e240: Light & & \\
\hline
\end{tabular}


Table 3 Synthesis of literature review of environmental factors positively (+), negatively (-) or not (0) associated with mobility and social participation in older adults (Continued)

\begin{tabular}{ll}
\hline Inadequate street lighting & $-[92],-[111],-[114]$ \\
Street lighting & $-[27],+[86],+[90],+[99],+[132]$ \\
e245: Time-related changes & $-[113]$ \\
Night time & \\
e250: Sound & $+[132]$ \\
Absence of noise & \\
e260: Air quality & $+[114]$ \\
Fresh air & $0[111]$ \\
Open sewers & $0[111]$
\end{tabular}

\section{Chapter 3: Support and relationships}

e310: Immediate family

Support from family

$+[87],+[123]$

$+[123]$

Support from friends

e325: Acquaintances, peers, colleagues, neighbors and community members

Children living in the neighborhood

$-[115]$

$-[113]$

Lack of social support

People

Social cohesion

Social support/network

Walking partner

e345: Stranger

Crowdedness

e350: Domesticated animals

Not having or not walking a dog

$+[86],+[102], 0[109],+[114],+[116],+[129]$

$+[95],+[119], 0[124]$

$+[99], 0[111], 0[115],+[134]$

+ [102]

0[109], $-[114]$

$-[111]$

\section{Chapter 4: Attitudes}

e445: Individual attitudes of strangers

Drivers' respect for pedestrians on crossings

Negative attitude of people

Disrespectful attitude of bus drivers

$-[113]$

$-[113]$

e460: Societal attitudes

Poor walking culture \& sidewalk etiquette
$+[87], 0[106],+[123]$

$0[106],+[123]$

$0[128]$

$-[113]$

$+[99],+[107]$

$+[71],+[107],+[117],+[128]$

\section{Chapter 5: Services, systems and policies}

e515: Architecture and construction services, systems and policies

Architectural features that facilitate social contacts $\quad+[108]$

e525: Housing services, systems and policies

Retirement home/housing facilities

$+[123]$

$+[123]$

e540: Transportation services, systems and policies

Car or driver's license

$+[87],+[99],+{ }^{* * *} /{ }^{+\S}[101],+[102],+[113], 0[115]$

$+[71],+[87],+[113],+[127], 0[128]$, $+[130],+[134]$

Inadequate public transportation

$-[110],-[113]$

$-[113],-[110]$

$+{ }^{+\dagger \dagger}[101],+{ }^{+\dagger+\dagger} / 0[116],+{ }^{+\S}[135]$ 
Table 3 Synthesis of literature review of environmental factors positively (+), negatively (-) or not (0) associated with mobility and social participation in older adults (Continued)

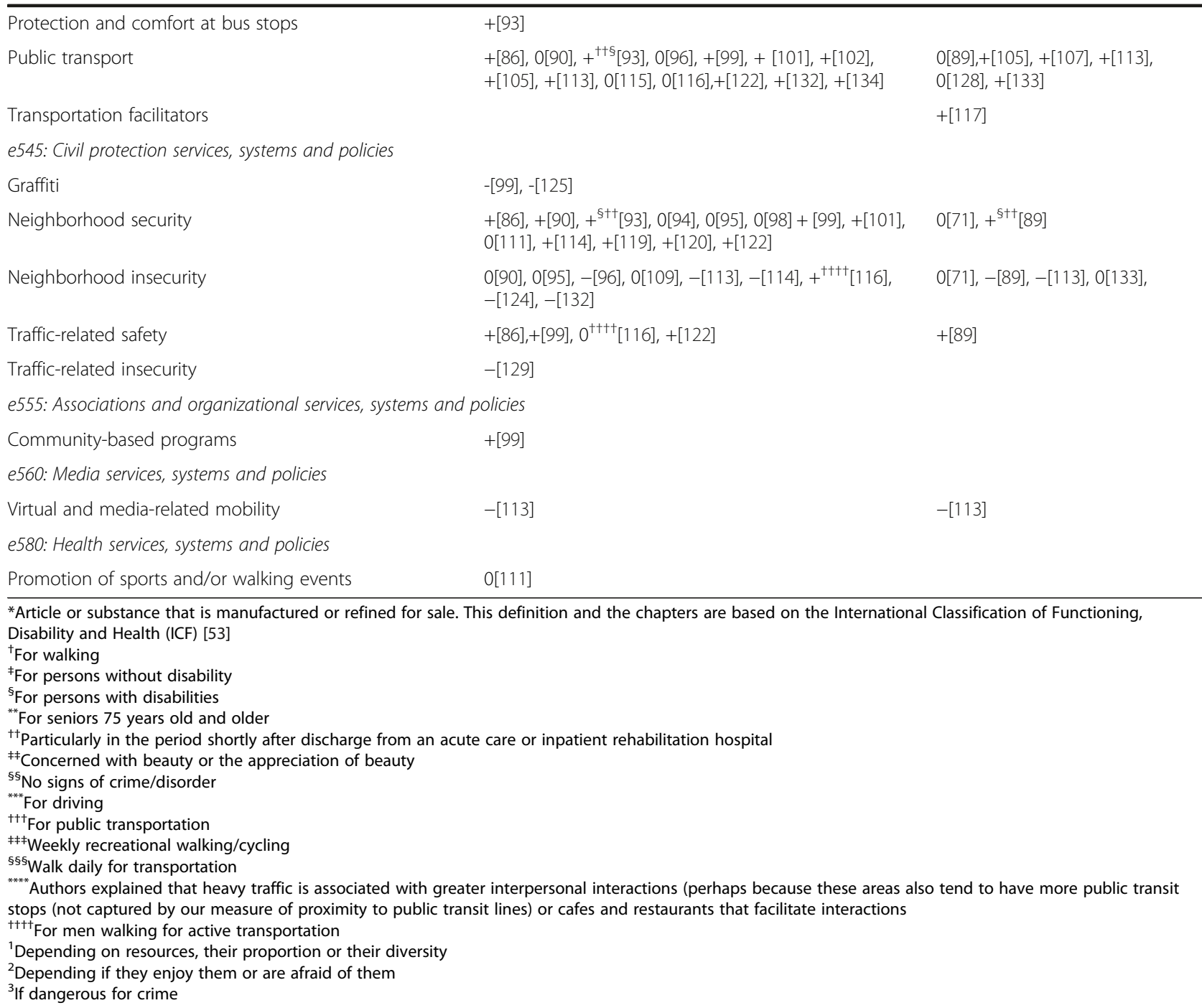

Streets in poor condition was negatively associated with social participation (Table 3).

Among 'Natural and human-made environment', studies considered principally 'Population' (15; $30 \%$ ) and 'Flora and fauna' (11; $22 \%)$. Mobility was mainly positively associated with Nature and green space, and Street lighting, and negatively with Traffic and Poor weather conditions (Table 3). Studies on 'Support and relationships' focused on 'Acquaintances, peers, colleagues, neighbors and community members' (18; $36 \%)$ and found that People and Social support/network were both positively associated with mobility and social participation. As very few of them concerned 'Attitudes', no association was confirmed by more than one study (Table 3). Finally, studies on 'Services, systems and policies' mainly considered 'Transportation services, systems and policies' (25; $50 \%)$ and 'Civil protection services, systems and policies' (24; 48 \%). Mobility and social participation were both mainly positively associated with Having a car or driver's license, Public transportation and Neighborhood security, and negatively with Neighborhood insecurity (Table 3 ). No or only one car for the dwelling and Traffic-related safety were associated, respectively, positively and negatively with mobility.

\section{Discussion}

This study provided a comprehensive understanding of neighborhood environment associations with mobility, i.e. the ability to move oneself within community environments [4], and social participation, i.e. a person's involvement in social activities that provide social interactions within his/her community or society' [29], in older adults. Mobility and social participation were both mainly positively associated with Proximity to 
resources and to recreational facilities, Social support, Car or driver's license, Public transportation and Neighborhood security, and negatively with Poor user-friendliness of the walking environment and Neighborhood insecurity. For example, living in close proximity to services [68] was shown to be important in performing activities to meet daily needs, including access to food shopping, health services, public transportation, banking and social clubs, and initiating and maintaining social links with community members [70]. Older adults living in resource affluent areas are less likely to have low levels of social functioning, independently of individual demographic and socioeconomic characteristics [71]. Moreover, having sufficient and convenient local business stores in the neighborhood allows older adults to remain active, which is beneficial for their health and may lead to longer independent living. The absence or disappearance of local businesses making it impossible for older adults to walk to these resources is a concern [86], especially when they prefer or are restricted to the immediate neighborhood [87]. Such results highlight the importance of urban planning interventions for neighborhood revitalization and for survival of proximity resources, limiting the creation of large supermarkets far from people's homes [88]. Such an absence is worrying since it is known that more proximate characteristics in one's immediate environment are more salient than characteristics in the wider neighborhood area [89].

Although associations of mobility and social participation with resource proximity were usually positive, few non-existent associations with mobility were found, illustrating the complexity of this type of study. One study found that the effects of neighborhood attributes on within-neighborhood recreational walking were stronger in less educated participants [90]. In another study, mobility was associated with greater diversity in recreational destinations only in neighborhoods with no signs of crime/disorder or stray animals [90]. Food and grocery stores were also associated with mobility, at least in the absence of path obstructions or sloping streets. In fact, the availability of resources may promote within-neighborhood walking for transportation, while recreational facilities and public transit points may facilitate overall walking [90]. However, destination-rich neighborhoods also need to provide a safe and physically unchallenging walking environment. Complexity is also highlighted by the fact that in green space living environments, facilities such as shops are further away and people use a car more often to reach resources [91]. For instance, interaction between neighborhood effects and individual characteristics, as described in the Glass and Balfour model, may be observed.

Moreover, this study highlighted the fact that few studies considered the context of persons with disabilities, which warrants further special attention. Such a context was particular and different. For example, contrary to people without disabilities, the mobility of persons with disabilities was negatively associated with neighborhoods having escalators, curbs, uneven surfaces, streets with traffic lights and busy, crowded places with high traffic density (people or objects), as well as poor weather conditions (snow and ice; cold and rainy) and unfamiliar places [92]. One study found that mobility of disadvantaged older adults was positively associated with it being safe to walk, public transportation and proximity of resources [93], while another did not support this latter association [94]. Low neighborhood socioeconomic status was positively associated with mobility $[95,96]$. Social participation of persons with disabilities was negatively associated with neighborhoods with streets in poor condition [97], but positively with traffic and residential security [89]. Finally, these conflicting results might suggest that among older adults with disabilities, mobility was more related to personal and intrinsic physical capacities than to the perceived environment [98]. Future research should focus on the context of persons with disabilities.

As it is critical to consider not just how older adults use resources but also how they get to them [99], more neighborhood studies on both mobility and social participation are needed. Even if the best resources are available, older adults, especially those with varying mobility challenges, will not use them if they cannot get to them easily and safely. First, public transportation including adequate public transit or other shared options is critical [99], especially for older adults who cannot walk long distances or have stopped driving. Social exclusion of older adults is reinforced by an inadequate public transit system or one that cannot adequately serve the entire municipality [100]. Although it is not a preferred mode for older adults having a car and a driver's license [101], there is a need to develop a more efficient public transit system since the location of resources can only change slowly. Second, seeing other people or social support is important. More alternative transportation solutions and personalized accompaniment to activities might also foster mobility and social participation. Since older adults might be more likely to be mobile or participate when activities are meaningful to them [99], the impact of seeing other people walking or doing social activities should not be underestimated. Such surroundings help to prevent victimization and provide assistance in case of a health emergency or fall [102]. Moreover, integrating older adults into their community can provide them with emotional support, motivation, information, social interaction, friendship, sense of belonging, etc. 


\section{Strengths and limitations}

Based on an international classification considering a wide range of environmental attributes, this study used a rigorous methodological framework for scoping studies [79-82], including a systematic and comprehensive retrieval of studies on the neighborhood environment, mobility and social participation from numerous multidisciplinary databases. In addition, results from quantitative studies were completed and extended by results from qualitative studies [103], which help to understand how the neighborhood environment influences mobility and social participation. Enriched by the close collaboration of knowledge-users from different fields (public health, urban planning, transportation planning, rehabilitation and gerontology) in a variety of institutions (academic, health and social services agencies, public transit authorities and municipalities), the results provide an accurate and up-to-date synthesis of the literature on how the neighborhood environment is associated with or influences mobility and social participation in older adults. Moreover, attributes not covered by previous research on the influence of the neighborhood environment on mobility and social participation were identified to inform future interdisciplinary research. However, as in other scoping studies [79], the current study does not systematically combine empirical results of previous studies or provide a detailed appraisal of the quality of the evidence. Furthermore, although the impact of not using textbooks should be minimal since they are generally not a primary source of empirical results, information available in them may have been missed. Although carefully reviewed and identified by two research assistants, retrieval of studies on the neighborhood environment, mobility and social participation was challenging as there are numerous associated key words and some of them (e.g., walk) generated many irrelevant results. Finally, as definitions and measures of neighborhood environment, mobility and social participation differ greatly across studies, results should be interpreted with caution although the synthesis involved many specifications.

\section{Conclusion}

Results from this comprehensive synthesis of empirical studies on the association of the neighborhood environment with mobility and social participation may ultimately support best practices, decisions and the development of innovative inclusive public health interventions including clear guidelines for the creation of age-supportive environments. To foster mobility and social participation, these interventions must consider Proximity to resources and to recreational facilities, Social support, Transportation, Neighborhood security and User-friendliness of the walking environment. These results will ultimately help to promote community-driven development [104] or active living in older adults, which are among the main goals of public health specialists. For example, decision-makers in the municipality can use results from this scoping study to support projects or make decisions about financial investments in urban planning and public safety (modifications to the neighborhood environment that encourage mobility and social participation). This information will also be useful for making policy recommendations related to land use planning and transportation, to assist in senior-friendly developments, redevelopments, revitalization plans and neighborhood improvements, and to design effective senior health interventions with an emphasis on neighborhood design influences and their location [105].

Future studies should examine mobility and social participation simultaneously, and investigate how they are associated with 'Attitudes', and 'Services, systems and policies' in older adults, including in disadvantaged older adults. This scoping study represents the first stage of a research program to: 1) identify key age- and genderspecific neighborhood environment determinants of mobility and social participation, controlling for individual factors such as tobacco use, body composition (obesity, nutrition) and energy expenditure (physical exercise); 2) develop health-related analytical geomatic tools (interactive atlas) that monitor these relevant neighborhood environmental features from extended continuous recordings; and 3) develop efficient knowledge transfer protocols for clinicians and decision-makers in the form of better clinical toolkits (scales or portable devices) for assessing the impact of intervention strategies on mobility and social participation. Finally, future studies on mobility and social participation need to use innovative ways to collect data. In addition to Photovoice [99] and Walk-along interviews to and from a destination (e.g. a shop) located within a 15-min walk from the participant's home [86] used previously, increasingly a geographic information system should be used [88]. These studies will eventually lead to the development of specific intervention strategies, including more comprehensive legislation and policies that can prevent mobility and social participation inequalities by optimizing neighborhood environment issues to improve health and quality of life in the population in general and especially in the older population.

\section{Appendix 1}

Definitions of environmental factors according to the International Classification of Functioning, Disability and Health (ICF) [53].

Chapter 1: Products and technology: This chapter is about the natural or human-made products or systems of products, equipment and technology in an individual's immediate environment that are gathered, created, produced or manufactured. The ISO 9999 classification of technical aids defines these as "any product, instrument, 
equipment or technical system used by a disabled person, especially produced or generally available, preventing, compensating, monitoring, relieving or neutralizing" disability. It is recognized that any product or technology can be assistive. (See ISO 9999: Technical aids for disabled persons-Classification (second version); ISO/ TC 173/SC 2; ISO/DIS 9999 (rev.).) For the purposes of this classification of environmental factors, however, assistive products and technology are defined more narrowly as any product, instrument, equipment or technology adapted or specially designed for improving the functioning of a disabled person.

Chapter 2: Natural environment and human-made changes to environment: This chapter is about animate and inanimate elements of the natural or physical environment, and components of that environment that have been modified by people, as well as characteristics of human populations within that environment.

Chapter 3: Support and relationships: This chapter is about people or animals that provide practical physical or emotional support, nurturing, protection, assistance and relationships to other persons, in their home, place of work, school or at play or in other aspects of their daily activities. The chapter does not encompass the attitudes of the person or people that are providing the support. The environmental factor being described is not the person or animal, but the amount of physical and emotional support the person or animal provides.

Chapter 4: Attitudes: This chapter is about the attitudes that are the observable consequences of customs, practices, ideologies, values, norms, factual beliefs and religious beliefs. These attitudes influence individual behaviour and social life at all levels, from interpersonal relationships and community associations to political, economic and legal structures; for example, individual or societal attitudes about a person's trustworthiness and value as a human being that may motivate positive, honorific practices or negative and discriminatory practices (e.g. stigmatizing, stereotyping and marginalizing or neglect of the person). The attitudes classified are those of people external to the person whose situation is being described. They are not those of the person themselves. The individual attitudes are categorized according to the kinds of relationships listed in Environmental Factors Chapter 3. Values and beliefs are not coded separately from the attitudes as they are assumed to be the driving forces behind the attitudes.

Chapter 5: Services, systems and policies: This chapter is about:

1. Services that provide benefits, structured programmes and operations, in various sectors of society, designed to meet the needs of individuals. (Included in services are the people who provide them.) Services may be public, private or voluntary, and may be established at a local, community, regional, state, provincial, national or international level by individuals, associations, organizations, agencies or governments. The goods provided by these services may be general or adapted and specially designed.

2. Systems that are administrative control and organizational mechanisms, and are established by governments at the local, regional, national, and international levels, or by other recognized authorities. These systems are designed to organize, control and monitor services that provide benefits, structured programmes and operations in various sectors of society.

3. Policies constituted by rules, regulations, conventions and standards established by governments at the local, regional, national, and international levels, or by other recognized authorities. Policies govern and regulate the systems that organize, control and monitor services, structured programmes and operations in various sectors of society.

\section{Appendix 2}

Attributes of the neighborhood environment not covered by previous selected studies on mobility or social participation in older adults

Chapter 1: Product and technology*

e110: Products or substances for personal consumption e115: Products and technology for personal use in daily living

e130: Products and technology for education

e135: Products and technology for employment

e145: Products and technology for the practice of religion and spirituality

Chapter 2:Natural environment and human-made changes to environment

e230: Natural events

e235: Human-caused events

e255: Vibration

Chapter 3: Support and relationships

e315: Extended family

e330: People in positions of authority

e335: People in subordinate positions

e340: Personal care providers and personal assistants

e355: Health professionals

e360: Other professionals

Chapter 4: Attitudes 
e410: Individual attitudes of immediate family members e415: Individual attitudes of extended family members e420: Individual attitudes of friends

e425: Individual attitudes of acquaintances, peers, colleagues, neighbors and community members

e430: Individual attitudes of people in positions of authority

e435: Individual attitudes of people in subordinate positions

e440: Individual attitudes of personal care providers and personal assistants

e450: Individual attitudes of health professionals

e455: Individual attitudes of health-related professionals

Chapter 5: Services, systems and policies

e510: Services, systems and policies for the production of consumer goods

e520: Open space planning services, systems and policies

e530: Utilities services, systems and policies

e535: Communication services, systems and policies

e550: Legal services, systems and policies

e565: Economic services, systems and policies

e570: Social security services, systems and policies

e575: General social support services, systems and policies

e585: Education and training services, systems and policies

e590: Labour and employment services, systems and policies

e595: Political services, systems and policies

*Based on the International Classification of Functioning, Disability and Health (ICF) [53]

\section{Competing interests}

The authors declare that they have no competing interests.

\section{Authors' contributions}

$M L$ drafted the manuscript. MG, JFB, AV, EC, CB and MMB helped draft and extensively revised the manuscript. MG, JFB, AV, EC and MMB verified classification of the results. All authors have approved the final manuscript and are willing to take responsibility for appropriate portions of the content.

\section{Acknowledgements}

This study is supported by the Canadian Institutes of Health Research [\#KAS-116 630]. Mélanie Levasseur is a FRQS junior 1 researcher (grant no. 26815). Thanks to Josiane Desroches, Francis Lacasse and Sarah Blain for their work.

\section{Author details}

${ }^{1}$ University of Sherbrooke, 2500 University Blvd., J1K 2R1 Sherbrooke, QC, Canada. ${ }^{2}$ Research Centre on Aging, Health and Social Services Centre University Institute of Geriatrics of Sherbrooke, 1036 Belvedere South, $\mathrm{J} 1 \mathrm{H}$ 4C4 Sherbrooke, QC, Canada. ${ }^{3}$ Public Health Department, Health and Social Services Agency, 300 King East, Suite 300, J1J 1B1 Sherbrooke, QC, Canada. ${ }^{4}$ Montreal Polytechnique, Downtown Station, P.O. Box 6079, H3C 3A7 Montreal, QC, Canada. ${ }^{5}$ Research Centre, CHUS, 3001 12th Avenue North, J1H 5N4 Sherbrooke, QC, Canada. ${ }^{6}$ Ordre des urbanistes du Québec, H2Y 3V4, Montreal, QC, Canada.
Received: 8 October 2014 Accepted: 6 May 2015

Published online: 23 May 2015

\section{References}

1. World Health Organization: http://www.who.int/features/factfiles/ageing/ ageing_facts/en/ 2014

2. Turcotte M, Schellenberg G. A portrait of seniors in Canada 2006. Statistics Canada: Ottawa; 2007.

3. Rowe JW, Kahn RL. Successful aging. Gerontologist. 1997;37(4):433-40

4. Webber SC, Porter MM, Menec VH. Mobility in older adults: a comprehensive framework. The Gerontologist. 2010;50(4):443-50.

5. Gardener EA, Huppert FA, Guralnik JM, Melzer D. Middle-aged and mobilitylimited: prevalence of disability and symptom attributions in a national survey. J Gen Intern Med. 2006;21(10):1091-6.

6. TopinkovÃ $\tilde{A}_{j}$ : Aging, disability and frailty. Ann Nutr Metab 2008, 52 Suppl 1:6-11.

7. Statistics Canada: Disability in Canada: A 2001 Profile. N 89-577-XIF. 2001.

8. Bouchard DR, Beliaeff S, Dionne IJ, Brochu M. Fat mass but not fat-free mass is related to physical capacity in well-functioning older individuals: nutrition as a determinant of successful aging (NuAge)-the Quebec Longitudinal Study. The journals of gerontology. 2007;62(12):1382-8.

9. Koster A, Patel K, Visser M, van Eijk J, Kanaya A, de Rekeneire N, et al. Joint effects of adiposity and physical activity on incident mobility limitation in older adults. Journal of the American Geriatrics Society. 2008;56(4):636-43.

10. Koster A, Penninx B, Newman A, Visser M, van Gool C, Harris T, et al. Lifestyle factors and incident mobility limitation in obese and non-obese older adults. Obesity. 2007;15(12):3122-32.

11. Yeom HA, Fleury J, Keller C. Risk factors for mobility limitation in community-dwelling older adults: a social ecological perspective. Geriatric nursing. 2008;29(2):133-40.

12. Ramsay SE, Whincup PH, Shaper AG, Wannamethee SG. The relations of body composition and adiposity measures to ill health and physical disability in elderly men. American journal of epidemiology. 2006;164(5):459-69.

13. Patla AE, Shumway-Cook A. Dimensions of mobility: defining the complexity and difficulty associated with community mobility. Jof Aging \& Phys Activity. 1999;7(1):7-19.

14. Hirvensalo M, Rantanen T, Heikkinen E. Mobility difficulties and physical activity as predictors of mortality and loss of independence in the community-living older population. Journal of the American Geriatrics Society. 2000;48(5):493-8.

15. Brach JS, VanSwearingen JM. Physical impairment and disability: relationship to performance of activities of daily living in community-dwelling older men. Phys Ther. 2002;82(8):752-61.

16. Guralnik JM, Ferrucci L, Pieper CF, Leveille SG, Markides KS, Ostir GV, et al. Lower extremity function and subsequent disability: consistency across studies, predictive models, and value of gait speed alone compared with the short physical performance battery. The journals of gerontology. 2000;55(4):M221-231.

17. Beswick AD, Rees K, Dieppe P, Ayis S, Gooberman-Hill R, Horwood J, et al. Complex interventions to improve physical function and maintain independent living in elderly people: a systematic review and meta-analysis. Lancet. 2008:371(9614):725-35.

18. Tooth L, Russell A, Lucke J, Byrne G, Lee C, Wilson A, et al. Impact of cognitive and physical impairment on carer burden and quality of life. Qual Life Res. 2008;17(2):267-73.

19. Warburton DE, Gledhill N, Quinney A. Musculoskeletal fitness and health. Canadian journal of applied physiology = Revue canadienne de physiologie appliquee. 2001;26:217-37.

20. Clausen T, Wilson AO, Molebatsi RM, Holmboe-Ottesen G. Diminished mental- and physical function and lack of social support are associated with shorter survival in community dwelling older persons of Botswana. BMC public health. 2007;7:144

21. Inouye SK, Peduzzi PN, Robison JT, Hughes JS, Horwitz RI, Concato J. Importance of functional measures in predicting mortality among older hospitalized patients. JAMA. 1998;279(15):1187-93.

22. Liu-Ambrose T, Ashe MC, Marra C. Conditions Research Team PA: Among older adults with multiple chronic conditions, physical activity is independently and inversely associated with health care utilization. Brit J Sports Med. 2008;44(14):1024-8

23. Mathieson KM, Kronenfeld JJ, Keith VM. Maintaining functional independence in elderly adults: the roles of health status and financial 
resources in predicting home modifications and use of mobility equipment. Gerontologist. 2002;42(1):24-31.

24. WHO Regional Office for Europe: A Physically Active Life Through Everyday Transport [http://www.euro.who.int/_data/assets/pdf_file/0011/87572/ E75662.pdf]. 2002.

25. Frank LD, Greenwald MJ, Winkelman S, Chapman J, Kavage S. Carbonless footprints: promoting health and climate stabilization through active transportation. Prev Med. 2010;50:S99-S105.

26. Turcotte M: Seniors' access to transportation. In: Canadian Social Trends. vol. 11-008: Statistics Canada; 2006: 43-50.

27. Shumway-Cook A, Patla AE, Stewart A, Ferrucci L, Ciol MA, Guralnik JM Environmental demands associated with community mobility in older adults with and without mobility disabilities. Phys Ther. 2002;82(7):670-81.

28. Sauermann S, Standhardt H, Gerschlager W, Lanmuller H, Alesch F. Kinematic evaluation in Parkinson's disease using a hand-held position transducer and computerized signal analysis. Acta Neurochir (Wien). 2005;147(9):939-45. discussion 945.

29. Levasseur M, Richard L, Gauvin L, Raymond É. Inventory and analysis of definitions of social participation found in the aging literature: Toward a taxonomy of social participation. Soc Sci Med. 2010;71(12):2141-9.

30. Bath PA, Deeg DJ. Social engagement and health outcomes among older people: introduction to a special section. Eur J Ageing. 2005:2:24-30.

31. Zunzunegui MV, Alvarado BE, Del Ser T, Otero A. Social networks, social integration, and social engagement determine cognitive decline in community-dwelling Spanish older adults. J Gerontol B Psychol Sci Soc Sci. 2003:58(2):S93-S100.

32. Verdonschot MML, de Witte LP, Reichrath E, Buntinx WHE, Curfs LMG. Impact of environmental factors on community participation of persons with an intellectual disability: a systematic review. J Intellect Disabil Res. 2009:53(1):54-64

33. Hamzat TK, Kobiri A. Effects of walking with a cane on balance and social participation among community-dwelling post-stroke individuals. Eur J Phys Rehab Med. 2008;44(2):121-6.

34. Desrosiers J, Robichaud L, Demers L, Gelinas I, Noreau L, Durand D. Comparison and correlates of participation in older adults without disabilities. Arch Gerontol Geriatr. 2009:49(3):397-403.

35. Desrosiers J, Noreau L, Rochette A. Social participation of older adults in Quebec. Aging Clinical and Experimental Research. 2004;16:406-12.

36. Berkman LF. The role of social relations in health promotion. Psychosom Med. 1995;57(3):245-54.

37. Berkman LF, Glass T, Brissette I, Seeman TE. From social integration to health: Durkheim in the new millennium. Soc Sci Med. 2000;51(6):843-57.

38. Rimmer JH, Riley B, Wang E, Rauworth A. Accessibility of health clubs for people with mobility disabilities and visual impairments. Am J Public Health. 2005;95(11):2022-8.

39. Fougeyrollas P: Le funambule, le fil et la toile. Québec, Canada: Transformations réciproques du sens du handicap [The tightrope walker, wire and canvas. Reciprocal transformations of the meaning of disability]. Presses de I'Université Laval; 2010.

40. D'Alisa S, Baudo S, Mauro A, Miscio G. How does stroke restrict participation in long-term post-stroke survivors? Acta Neurol Scand. 2005;112(3):157-62.

41. Jette AM, Keysor J, Coster W, Ni P, Haley S. Beyond function: predicting participation in a rehabilitation cohort. Arch Phys Med Rehabil. 2005;86(11):2087-94

42. Rochette A, Desrosiers J, Noreau L. Association between personal and environmental factors and the occurrence of handicap situations following a stroke. Disabil Rehabil. 2001:23(13):559-69.

43. Harwood RH, Gompertz P, Ebrahim S. Handicap one year after a stroke: validity of a new scale. J Neurol Neurosurg Psychiatry. 1994;57(7):825-9.

44. Bourdeau I, Desrosiers J, Gosselin S. Predictors of reintegration to normal living in older adults discharged from an intensive rehabilitation program. Int J Rehabil Res. 2008;31(4):267-74.

45. Clarke PJ, Black SE, Badley EM, Lawrence JM, Williams JI. Handicap in stroke survivors. Disabil Rehabil. 1999;21(3):116-23.

46. Sturm JW, Dewey HM, Donnan GA, Macdonell RA, McNeil JJ, Thrift AG. Handicap after stroke: how does it relate to disability, perception of recovery, and stroke subtype?: the North East Melbourne Stroke Incidence Study (NEMESIS). Stroke. 2002;33(3):762-8.

47. Everard KM, Lach HW, Fisher EB, Baum MC. Relationship of activity and social support to the functional health of older adults. J Gerontol B Psychol Sci Soc Sci. 2000;55(4):S208-212.
48. Levasseur M, Desrosiers J, St-Cyr Tribble D. Do quality of life, participation and environment of older adults differ according to level of activity? Health and Quality of Life Outcomes. 2008:6:30.

49. De Haan R, Horn J, Limburg M, Van Der Meulen J, Bossuyt P. A comparison of five stroke scales with measures of disability, handicap, and quality of life. Stroke. 1993;24(8):1178-81.

50. Wilkie R, Peat G, Thomas E, Croft P. Factors associated with participation restriction in community-dwelling adults aged 50 years and over. Qual Life Res. 2007;16(7):1147-56.

51. Lawton MP (ed.): Environment and aging (2nd edition). Monterey: Brooks/ Cole; 1986.

52. Law MC. The environment: a focus for occupational therapy. Can J Occup Ther. 1991;58(4):171-9.

53. World Health Organization (ed.): International Classification of Functioning Disability and Health. Geneva, Switzerland: WHO; 2001.

54. Murata C, Kondo T, Tamakoshi K, Yatsuya H, Toyoshima H. Factors associated with life space among community-living rural elders in Japan. Public Health Nurs. 2006;23(4):324-31.

55. Xue Q, Fried L, Glass TA, Laffan A, Chaves P. Life-space constriction, development of frailty, and the competing risk of mortality: the Women's Health And Aging Study I. American journal of epidemiology. 2008;167(2):240-8.

56. Glass TA, Balfour JL: Neighborhoods, aging, and functional limitations. In: Neighborhoods and health. edn. Edited by Kawachi I, Berkman LF. New York: Oxford University Press; 2003: 303-334.

57. Davison KK, Lawson CT. Do attributes in the physical environment influence children's physical activity? A review of the literature Int Jof Behav Nutr Phys Act. 2006;3:19

58. Abu-Rayya HM. Depression and social involvement among elders. The Internet Journal of Health. 2006:5(1):9.

59. Meriano C, Latella D. Occupational Therapy Interventions. Function and Occupations Thorofare, NJ: SLACK Incorporated. 2008;423-455.

60. Fujiwara Y, Watanabe N, Nishi M, Ohba H, Lee S, Kousa Y, et al. Sakuma N et al: [Indirect effects of school volunteering by senior citizens on parents through the "REPRINTS" intergenerational health promotion program]. Nippon Koshu Eisei Zasshi. 2010;57(6):458-66.

61. World Health Organization. Global age-friendly cities: a guide. Geneva, Switzerland: World Health Organization; 2007.

62. Carp FM: Neighborhood quality perception and measurement. In: Housing an aging society: Issues, alternatives, and policy. edn. Edited by Newcomer RJ, Lawton P, Byerts TO. New York: Van Nostrand Reinhold Company; 1986: 127-140.

63. Albrecht GL, Devlieger PJ. The disability paradox: High quality of life against all odds. Soc Sci Med. 1999;48:977-88.

64. Richards JS, Bombardier CH, Tate D, Dijkers M, Gordon W, Shewchuk R, et al. Access to the environment and life satisfaction after spinal cord injury. Arch Phys Med Rehabil. 1999;80(11):1501-6.

65. Verbrugge LM, Rennert C, Madans JH. The great efficacy of personal and equipment assistance in reducing disability. Am J Public Health. 1997:87(3):384-92.

66. Vik K, Lilja M, Nygard L. The influence of the environment on participation subsequent to rehabilitation as experienced by elderly people in Norway. Scand J Occup Ther. 2007;14(2):86-95.

67. Horowitz BP. Occupational therapy home assessments: Supporting community living through client-centered practice. Occup Ther Mental Health. 2002;18(1):1-17.

68. Walker RB, Hiller JE. Places and health: A qualitative study to explore how older women living alone perceive the social and physical dimensions of their neighbourhoods. Soc Sci Med. 2007;65(6):1154-65.

69. Baum F. Palmer C: 'Opportunity structures': urban landscape, social capital and health promotion in Australia. Health Promot Int. 2002;17(4):351-61.

70. Lindström M, Moghaddassi M, Merlo J. Individual self-reported health, social participation and neighbourhood: A multilevel analysis in Malmö. Sweden Prev Med. 2004:39(1):135-41.

71. Bowling A, Stafford M. How do objective and subjective assessments of neighbourhood influence social and physical functioning in older age? Findings from a British survey of ageing. Soc Sci Med. 2007:64(12):2533-49.

72. Clarke PJ, Ailshire JA, Lantz P. Urban built environments and trajectories of mobility disability: findings from a national sample of community-dwelling American adults (1986-2001). Soc Sci Med. 2009;69(6):964-70. 
73. Burke J, O'Campo P, Salmon C, Walker R. Pathways connecting neighborhood influences and mental well-being: Socioeconomic position and gender differences. Soc Sci Med. 2009;68(7):1294-304.

74. Brown S, Mason CA, Perrino T, Lombard J, Martinez F, Plater-Zyberk E, et al. Built environment and physical functioning in Hispanic elders: the role of "eyes on the street". Environ Health Perspect. 2008;116(10):1300-7.

75. Frank LD, Andresen MA, Schmid TL. Obesity relationships with community design, physical activity, and time spent in cars. Am J Prev Med. 2004;27(2):87-96.

76. Institute of Medicine and Transportation Research Board of the National Academies: Does the built environment influence physical activity? Examining the evidence. Report No 282 Washington, DC:National Academy of Sciences 2005.

77. Leyden KM. Social capital and the built environment: the importance of walkable neighborhoods. Am J Public Health. 2003;93(9):1546-51.

78. Jacobs J. The death and life of great American cities. New York: Vintage Books, repr. 1992;1961.

79. Arksey H, O'Malley L: Scoping studies: Towards a methodological framework Int J Soc Res Methodol 2005, 8(1):19-32.

80. Levack WM. Ethics in goal planning for rehabilitation: a utilitarian perspective. Clin Rehabil. 2009;23(4):345-51.

81. Colquhoun HL, Letts LJ, Law MC, MacDermid JC, Missiuna CA. A scoping review of the use of theory in studies of knowledge translation. Can J Occup Ther. 2010;77(5):270-9.

82. Anderson S, Allen P, Peckham S, Goodwin N. Asking the right questions: scoping studies in the commissioning of research on the organisation and delivery of health services. Health Res Policy Syst. 2008;6:7.

83. Levasseur M, Généreux M, Desroches J, Carrier A, Lacasse F, Beaulac C, Chabot É, Abecia A, Gosselin L, Vanasse A: How to find lessons from the public health literature: example of a scoping study protocol on the neighbourhood environment. International Journal of Preventive Medicine 2015, 6(1):[Epub ahead of print]

84. Moher D, Liberati A, Tetzlaff J, Altman DG. The PRISMA Group: Preferred Reporting Items for Systematic Reviews and Meta-Analyses: The PRISMA Statement. PLoS Med. 2009;6(6), e1000097.

85. L'Écuyer R. Méthodologie de l'analyse développementale de contenu : méthode GPS et concept de soi [Methodology of developmental content analysis: GPS method and self concept]. Québec, QC: Presses de I'Université du Québec; 1990.

86. Van Cauwenberg J, Clarys P, De Bourdeaudhuij I, Van Holle V, Verte D, De Witte $\mathrm{N}$, et al. Physical environmental factors related to walking and cycling in older adults: the Belgian aging studies. BMC Health Public. 2012;12(1):142-54

87. Hovbrandt P, Fridlund B, Carlsson G. Very old people's experience of occupational performance outside the home: possibilities and limitations. Scand J Occup Ther. 2007;14(2):77-85.

88. Levasseur M, Gauvin L, Richard L, Kestens Y, Daniel M, Payette H, et al. Associations between perceived proximity to neighborhood resources, disability, and social participation among community-dwelling older adults: Results from the VoisiNuAge Study. Arch Phys Med Rehabil. 2011;92(12):1979-86.

89. Clarke PJ, Ailshire JA, Nieuwenhuijsen ER, de Kleijn-de Vrankrijker MW. Participation among adults with disability: the role of the urban environment. Soc Sc Med. 2011;72(10):1674-84.

90. Cerin E, Ka-yiu L, Barnett A, Sit CHP, Man-chin C, Wai-man C, et al. Walking for transportation in Hong Kong Chinese urban elders: a cross-sectional study on what destinations matter and when. Int J Behav Nutr \& Physl Act. 2013;10(1):78-87.

91. Maas J, Verheij RA, Spreeuwenberg P, Groenewegen PP. Physical activity as a possible mechanism behind the relationship between green space and health: a multilevel analysis. BMC public health. 2008:8:206.

92. Shumway-Cook A, Patla A, Stewart A, Ferrucci L, Ciol MA, Guralnik JM. Environmental components of mobility disability in community-living older persons. Journal of the American Geriatrics Society. 2003;51(3):393-8.

93. Gant R. Pedestrianisation and disabled people: a study of personal mobility in Kingston town centre. Disabil Soc. 1997;12(5):723-40.

94. Gauvin L, Riva M, Barnett T, Richard L, Craig CL, Spivock M, et al. Association between neighborhood active living potential and walking. American journal of epidemiology. 2008;167(8):944-53.

95. Fisher KJ, Li F, Michael Y, Cleveland M. Neighborhood-level influences on physical activity among older adults: a multilevel analysis. J Aging Phys Act. 2004;12(1):45-63.
96. Nagel $\mathrm{CL}$, Carlson NE, Bosworth M, Michael YL. The relation between neighborhood built environment and walking activity among older adults. American journal of epidemiology. 2008;168(4):461-8.

97. Clarke P, Ailshire JA, Bader M, Morenoff JD, House JS. Mobility disability and the urban built environment. American journal of epidemiology. 2008;168(5):506-13.

98. de Melo LL, Menec V, Porter MM, Ready AE. Personal factors, perceived environment, and objectively measured walking in old age. J Aging Phys Activity. 2010;18(3):280-92.

99. Chaudhury H, Mahmood A, Michael YL, Campo M, Hay K. The influence of neighborhood residential density, physical and social environments on older adults' physical activity: An exploratory study in two metropolitan areas. J Aging Studies. 2012;26(1):35-43.

100. Engels B, Liu G-J. Social exclusion, location and transport disadvantage amongst non-driving seniors in a Melbourne municipality. Australia J Transport Geography. 2011;19(4):984-96.

101. Cao X, Mokhtarian PL, Handy SL. Neighborhood design and the accessibility of the elderly: An empirical analysis in northern California. Int J Sustainable Transportation. 2010:4(6):347-71.

102. Grant TL, Edwards N, Sveistrup H, Andrew C, Egan M. Neighborhood walkability: older people's perspectives from four neighborhoods in Ottawa. Canada J Aging \& Phys Activity. 2010;18(3):293-312.

103. Popay J: Incorporing qualitative information in systematic reviews. Paper presented at the 14th Cochrane Colloquium, Dublin, Ireland. 2006.

104. Taylor M. Public policy in the community (2nd Edition). Palgrave Macmillan: New York, NY; 2011.

105. Michael YL, Green MK, Farquhar SA. Neighborhood design and active aging. Health \& Place. 2006;12(4):734-40.

106. Anaby D, Miller WC, Eng JJ, Jarus T, Noreau L. Can personal and environmental factors explain participation of older adults? Disabil Rehabil. 2009;31(15):1275-82.

107. Andonian L, MacRae A. Well older adults within an urban context: Strategies to create and maintain social participation. Br J Occup Ther. 2011;74(1):2-11.

108. Brown SC, Huang S, Perrino T, Surio P, Borges-Garcia R, Flavin K, et al. The relationship of perceived neighborhood social climate to walking in Hispanic older adults: a longitudinal, cross-lagged panel analysis. J Aging Health. 2011;23(8):1325-51.

109. Cerin E, Sit CH, Barnett A, Cheung MC, Chan WM. Walking for recreation and perceptions of the neighborhood environment in older Chinese urban dwellers. J Urban Health. 2013;90(1):56-66.

110. Conde MD. Leisure patterns and needs of the elderly in rural Galicia (Spain). Educ Gerontol. 2012;38(2):138-45.

111. Corseuil MW, Schneider IJ, Silva DA, Costa FF, Silva KS, Borges L, et al. Perception of environmental obstacles to commuting physical activity in Brazilian elderly. Prev Med. 2011;53(4-5):289-92.

112. Eronen J, Bonsdorff M, Rantakokko M, Rantanen T. Environmental facilitators for outdoor walking and development of walking difficulty in communitydwelling older adults. Eur J Ageing. 2014;11(1):67-75.

113. Fristedt S, Björklund A, Wretstrand A, Falkmer T. Continuing mobility and occupational participation outside the home in old age is an act of negotiation. Activities, Adaptation \& Aging. 2011;35(4):275-97.

114. Gallagher NA, Gretebeck KA, Robinson JC, Torres ER, Murphy SL, Martyn KK. Neighborhood factors relevant for walking in older, urban, African American adults. J Aging \& Phys Activity. 2010;18(1):99-115.

115. Gauvin L, Richard L, Kestens Y, Shatenstein B, Daniel M, Moore SD, et al. Living in a well-serviced urban area is associated with maintenance of frequent walking among seniors in the VoisiNuAge study. J Gerontol B Psych Sci Soc Sci. 2012;67B(1):76-88.

116. Inoue S, Ohya Y, Odagiri Y, Takamiya T, Kamada M, Okada S, et al. Perceived neighborhood environment and walking for specific purposes among elderly Japanese. J Epidemiol. 2011;21(6):481-90.

117. Keysor JJ, Jette AM, Coster W, Bettger JP, Haley SM. Association of environmental factors with levels of home and community participation in an adult rehabilitation cohort. Arch Phys Med Rehabil. 2006:87(12):1566-75.

118. Kweon B-S, Sullivan WC, Wiley AR. Green common spaces and the social integration of inner-city older adults. Environ Behav. 1998;30(6):832-58.

119. Li F, Fisher J, Brownson RC. A multilevel analysis of change in neighborhood walking activity in older adults. J Aging Phys Act. 2005;13(2):145-59.

120. Li F, Fisher KJ, Brownson RC, Bosworth M. Multilevel modelling of built environment characteristics related to neighbourhood walking activity in older adults. J Epidemiol Community Health. 2005;59(7):558-64. 
121. Lindstrom M, Merlo J, Ostergren PO. Individual and neighbourhood determinants of social participation and social capital: a multilevel analysis of the city of Malmo. Sweden Soc Sci Med. 2002;54(12):1779-91.

122. Lockett D, Willis A, Edwards N. Through seniors' eyes: an exploratory qualitative study to identify environmental barriers to and facilitators of walking. The Canadian journal of nursing research = Revue canadienne de recherche en sciences infirmieres. 2005;37(3):48-65.

123. Lord S, Després C, Ramadier T. When mobility makes sense: A qualitative and longitudinal study of the daily mobility of the elderly. J Environmental Psychology. 2011;31(1):52-61.

124. Mendes de Leon CF, Cagney KA, Bienias JL, Barnes LL, Skarupski KA, Scherr PA, Evans DA: Neighborhood social cohesion and disorder in relation to walking in community-dwelling older adults: a multilevel analysis. J Aging Health 2009, 21(1):155-171.

125. Michael Y, Beard T, Choi D, Farquhar S, Carlson N. Measuring the influence of built neighborhood environments on walking in older adults. J Aging Phys Act. 2006:14(3):302-12

126. Patterson PK, Chapman NJ. Urban form and older residents' service use, walking, driving, quality of life, and neighborhood satisfaction. Am J Health Prom. 2004;19(1):45-52

127. Richard L, Gauvin L, Gosselin C, Laforest S. Staying connected: neighbourhood correlates of social participation among older adults living in an urban environment in Montreal. Quebec Health Prom Int. 2009;24(1):46-57.

128. Richard L, Gauvin L, Kestens Y, Shatenstein B, Payette H, Daniel M, et al. Neighborhood resources and social participation among older adults: Results from the VoisiNuage Study. J Aging Health. 2013;25(2):296-318.

129. Strath S, Isaacs R, Greenwald MJ. Operationalizing environmental indicators for physical activity in older adults. J Aging Phys Activity. 2007;15(4):412-24.

130. Therrien FH, Desrosiers J. Participation of metropolitan, urban and rural community-dwelling older adults. Arch Gerontol Geriatr. 2010;51(3):e52-56.

131. Touboul P, Valbousquet J, Pourrat-Vanoni I, Alquier MF, Benchimol D, Pradier C: [Adapting the environment to encourage the elderly to walk: a qualitative study]. Sante Publique 2011, 23(5):385-399

132. Van Cauwenberg J, Van Holle V, Simons D, Deridder R, Clarys P, Goubert L, et al. Environmental factors influencing older adults' walking for transportation: a study using walk-along interviews. Int J Behav Nutr Phys Act. 2012;9(1):85-95.

133. White DK, Jette AM, Felson DT, Lavalley MP, Lewis CE, Torner JC, et al. Are features of the neighborhood environment associated with disability in older adults? Disabil Rehabil. 2010;32(8):639-45.

134. Yen IH, Shim JK, Martinez AD, Barker JC. Older people and social connectedness: How place and activities keep people engaged. J Aging Res. 2012;1-10.

135. Frank L, Kerr J, Rosenberg D, King A. Healthy aging and where you live: community design relationships with physical activity and body weight in older Americans. J Phys Act Health. 2010;7 Suppl 1:S82-90.

\section{Submit your next manuscript to BioMed Central and take full advantage of:}

- Convenient online submission

- Thorough peer review

- No space constraints or color figure charges

- Immediate publication on acceptance

- Inclusion in PubMed, CAS, Scopus and Google Scholar

- Research which is freely available for redistribution 